\title{
A virtual co-creation collaboration between a university physics research group and school students
}

\author{
Meirin Oan Evans ${ }^{1}$, Rosalinde Abrahams ${ }^{2}$, Darren Baskill ${ }^{1}$, Zoë Earnshaw ${ }^{1}$, Peter \\ Golton $^{2}$, Kate Shaw ${ }^{1}$, Thomas Stevenson ${ }^{1}$, Mark Sutton ${ }^{1}$, Stephen Wilkins ${ }^{1}$ \\ ${ }^{1}$ School of Mathematical and Physical Sciences, University of Sussex, Great Britain, ${ }^{2}$ Physics \\ Department, BHASVIC, Great Britain.
}

\begin{abstract}
This work aims to inspire, ignite and engage school students to consider STEM at university, by collaborating between a university research group and school students. Learning resources will be co-created with students, based on what they have learnt and their new ideas. These resources will be used to teach future students, in a multiplying effect. We specifically target a widening participation school. Numerous engagement techniques have been used to sustain participation whilst teaching online. Breakout rooms have been used extensively, to provide close interactions between researchers and students. Both male and female researchers deliver the project, to provide role models in particular for the girls amongst the students, who are in the minority. Surveys are being employed before, during and after the project to evaluate the evolution of students' attitudes towards STEM. Given the projected success of this pilot, plans are in place for a national roll-out of virtual co-creation collaborations.
\end{abstract}

Keywords: Teaching tools; educational technology; evaluation of student learning; science education; learning technology; co-creation. 


\section{Introduction}

At a time when many research outreach activities have been cancelled, our particle physics research group is providing an enriching activity for school students. We are pioneering an innovative online approach to teaching data analysis from the biggest particle physics experiment in the world (ATLAS Collaboration, 2008). The interface that students are met with is shown in Figure 1. Normally, this project would fit the blended learning model (Graham, 2006) - the intention was to meet face-to-face occasionally so students would be getting a rich experience. If possible, face-to-face-meetings will be pursued towards the end of the project. Ten 16-17-year-old students at a crucial stage of their learning, have been given the chance to enhance their extra-curricular activities (Eccles et al., 2003). The project is running over 6 months, providing an opportunity to scaffold the students' learning (Gibbons, 2002). The project is designed to be engaging and motivating, while giving students a safe yet challenging environment to tackle university-level material.

\section{$\equiv$ Tags \\ ATLAS Open Data \\ An Educational project in High Energy \\ Physics}

Home About Apps Data News/Blog Software
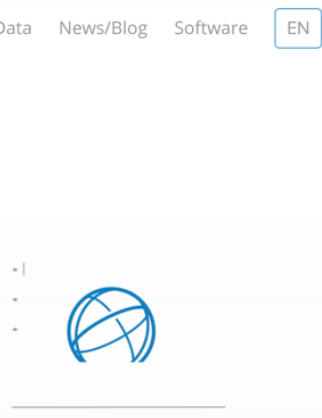

Figure 1. Homepage for the ATLAS Open Data website user interface.

\section{Aims and Planning}

The key objective of the project is to engage students with exciting, cutting-edge research. In doing so, we aim to motivate some to consider STEM at university (Carnevale et al, 2011). The project also hopes to address the widening gap between privileged and disadvantaged students. A key deliverable of the project is for the students to create a tailored online programme for students of similar ages to follow, giving a multiplying effect to our project in terms of students reached. This pilot programme is being used to co-create resources, establishing a partnership of discovery (Dollinger et al., 2018). Therefore, the research questions are two-fold: 
1. Can we develop a curriculum with participants to attract future students to choose STEM?

2. Can we facilitate participants' attitudes towards STEM by engaging them in the cocreation of learning materials?

We specifically work with a widening participation school - a school whose students are from groups (socio-economic, ethnic background, etc) that are under-represented in higher education (Burke, 2013). Over half their intake qualify for at least one widening participation scheme within the school. Students were chosen according to interest in particle physics, regardless of demographics. Some characteristics of the students involved are given in Table 1. An online programme gives the chance to work with students that may not be able to attend after school in person, for whatever reason. The project is relevant to students not only because of their natural curiosity and interest in physics at university but also because it has overlap with the specification they are following at school - particle physics, units of energy, magnetic fields, accelerating particles and more. 
Table 1. Some characteristics of the students involved, obtained from self-assessed anonymous survey data.

\begin{tabular}{|c|c|}
\hline Profile characteristic & Detail \\
\hline Age (years old) & $16(50 \%), 17(50 \%)$ \\
\hline Gender & 8 male, 2 female \\
\hline $\begin{array}{l}\text { Subjects studied at school, other } \\
\text { than physics and maths }\end{array}$ & $\begin{array}{l}\text { Further Maths (5), Chemistry (5), Computing (2), } \\
\text { Biology (1), Economics (1), Music (1), Spanish (1) }\end{array}$ \\
\hline Reasons for choosing physics & $\begin{array}{l}\text { Interest and enjoyment (8), Need for further study (3), } \\
\text { Knowledge/skills will help with further study/career (2), } \\
\text { Help application for further study (1) }\end{array}$ \\
\hline $\begin{array}{l}\text { Decided what they want to do } \\
\text { after school? }\end{array}$ & Yes $(50 \%)$, An idea but still considering options (50\%) \\
\hline $\begin{array}{l}\text { What do they hope to gain from } \\
\text { working with us? }\end{array}$ & $\begin{array}{l}\text { Experience of research (8), Learn about the ATLAS } \\
\text { experiment (8), Learn analysis skills (7), Opportunity to } \\
\text { make unique contribution (5), To add to CV/applications } \\
\text { (5), Opportunity to work with friends/peers on project } \\
\text { outside school (5), Learn programming (4), Nice online }\end{array}$ \\
\hline Problem solving level & hobbie (3) \\
\hline Particle physics theory level & $\begin{array}{l}\text { Above average (4), Average (3), Beginner (1), No } \\
\text { knowledge (1) }\end{array}$ \\
\hline $\begin{array}{l}\text { Particle physics experiment } \\
\text { knowledge }\end{array}$ & Above average (1), Average (2), Beginner (6) \\
\hline Level in using histograms & $\begin{array}{l}\text { Above average (1), Average (3), Beginner (4), No } \\
\text { knowledge (1) }\end{array}$ \\
\hline $\begin{array}{l}\text { Level in evaluating } \\
\text { uncertainties }\end{array}$ & Above average (6), Average (2), Beginner (1) \\
\hline $\begin{array}{l}\text { Knowledge level in } \mathrm{C}++ \\
\text { programming }\end{array}$ & $\begin{array}{l}\text { Above average (2), Average (6), Beginner (1) } \\
\text { Expert (1), Above average (2), Beginner (1), No }\end{array}$ \\
\hline $\begin{array}{l}\text { Knowledge level in Python } \\
\text { programming }\end{array}$ & $\begin{array}{l}\text { knowledge (5) } \\
\text { Expert (2), Above average (2), Beginner (2), No }\end{array}$ \\
\hline $\begin{array}{l}\text { Preference for independent or } \\
\text { group work }\end{array}$ & $\begin{array}{l}\text { knowledge (3) } \\
\text { Both (7), Independent (2) }\end{array}$ \\
\hline
\end{tabular}




\section{Current approach}

We use micro-talks (10-15 minutes) with key themes and educational messages to begin synchronous sessions, sometimes given to the students beforehand in a flipped-classroom style. Equipped with the key ideas, we want students to learn primarily through doing. We have used activities that encourage exploration, written in Table 2. With each activity, students were analysing proton-proton collision data, where information from the ATLAS experiment allows one to identify fundamental particles and measure their properties with associated uncertainties. Having worked through exploratory activities, students are codesigning the activities of Table 3 with us.

Table 2. Explanatory activities used during the project, along with their learning objectives.

\begin{tabular}{ll}
\hline Exploratory activity & Learning objective \\
\hline HYPATIA event display (Kourkoumelis \& & $\begin{array}{l}\text { Particle identification using the ATLAS } \\
\text { detector }\end{array}$ \\
Vourakis, 2014) & $\begin{array}{l}\text { Optimising for signal vs background } \\
\text { Histogram Analyser (ATLAS Collaboration, 2021) }\end{array}$ \\
Jupyter notebook (Kluyver et al., 2016) & Learning to code \\
\hline
\end{tabular}

Table 3. Activities co-developed with and for the students.

\begin{tabular}{ll}
\hline Activity developed & Learning objective \\
\hline Summary table of histogram analysis & Connection between tabular and graphical data \\
Analysis flowchart design & Understanding of steps in particle physics analysis \\
Real data measurement & Build upon skills learnt with simulated data \\
Question design & Ability to give student voice in written documentation \\
Curriculum link research & Connection between school and extra-curricular study \\
Documentation writing & Experience of preparing scientific documents \\
Documentation review & Experience of peer-review process in research \\
Explore with Excel & Develop skills in a common data analysis tool \\
How to rediscover the Higgs & Use computer programming to rediscover a particle \\
New-physics research & Review theories being actively researched by scientists \\
\hline
\end{tabular}

Adapting to an online environment has been challenging, but a learning process. Quality twoway engagement is maintained by various interactions through Microsoft Teams, a known 
pedagogical tool (Martin \& Tapp, 2019). Kahoot quizzes continue to be an effective participation tool (Wang \& Tahir, 2020). To give students more ownership over their learning, we ask them to design questions, see Figure 2. We also provide opportunities for students to present, helping them develop public-speaking skills. Altogether, this builds a low-threat-high-challenge climate, where students respond to challenges when they do not feel under pressure from teachers or peers. We do this in our project with offline research and collaboration between students. This technique is used by teachers in their lessons.

When making cuts to find the signal, should select b-tagged jets, or not b-tagged jet?

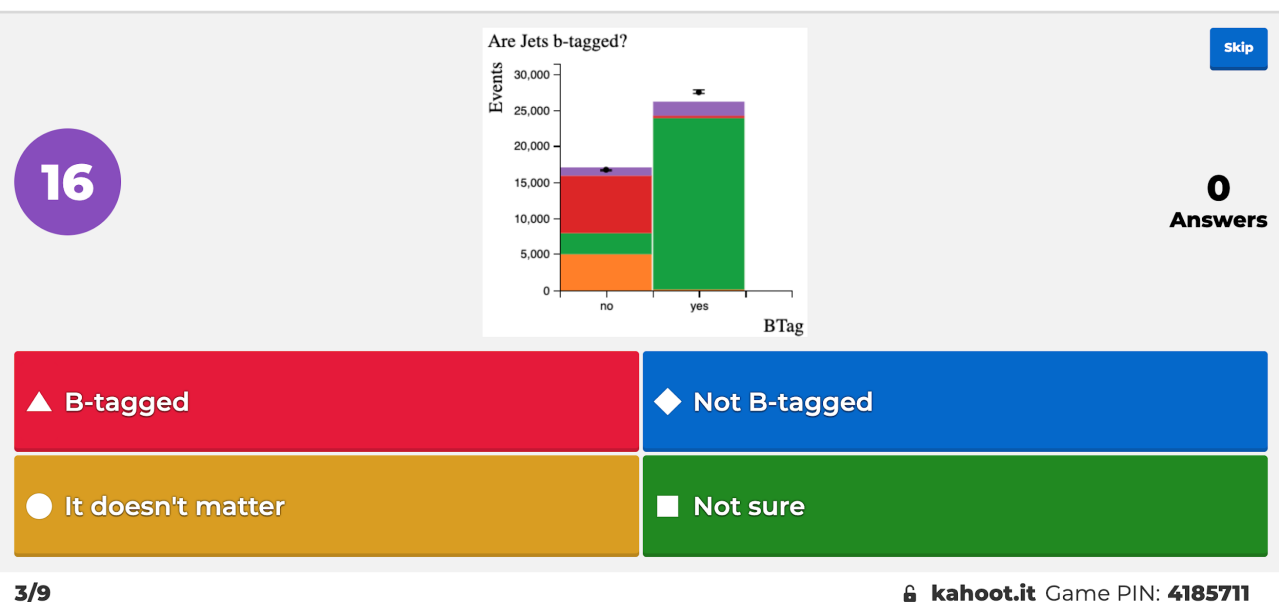

Figure 2. Example of a Kahoot quiz question asked to students as a starter activity during a live online session.

Breakout rooms have been key. Grouping two or three students and one researcher encourages peer-to-peer-learning, providing a supportive environment where students feel safe to share ideas and help develop confidence in group situations. It has been an invaluable experience for students to have close interactions with working researchers, while the learning is student-centred. Delivering via a variety of interaction techniques has also meant that we have been providing teacher Continuing Professional Development (CPD). The two teachers involved have learnt quite a bit from this activity and they report that it has given them some ideas for teaching next year and maybe using the resources themselves.

Since girls are in the minority among the students (2/10), we engage our target audience by showing female role models. Female researchers have led parts of the project throughout. We also engaged a university student, to enthuse the school students about university. We specifically employed a female student that excelled in laboratory modules at university. The Institute of Physics (IOP) showed that a good teacher was more important than a teacher of the same gender - i.e., a good male teacher who encourages girls into physics and is supportive can be very successful (Murphy \& Whitelegg, 2006). Even if all eight boys go 
onto STEM degrees at university, but neither girl does, the project would still be a success! Another point to add is that the most senior researcher is female. This is beneficial as projects where the senior people are male and gender balance is only achieved at junior level give less confidence to female students and reinforces the wrong idea that "men are leaders, women take part".

\section{Future evaluation}

Seeing students' evolution of attitudes towards STEM (before, during and after) will be helpful, although the sample size is relatively small. Pre-project, we surveyed the students' attitudes towards STEM. The project places an emphasis on skills, so we asked what skills they were expecting to learn, see Figure 3. A future longitudinal evaluation may indicate if we positively influenced students' choices of studying STEM. Surveys have been conducted in Google Forms, a proven platform for use in education (Brown \& Hocutt, 2015). Since this study is in progress, only the participants' attitude towards STEM before the project has been measured. The impact of the project will be evaluated in future.

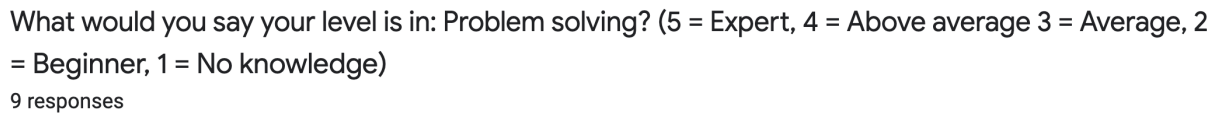

2

3

\section{$4(44.4 \%)$}

Figure 3. Histogram of responses to a question from the evaluation survey given to students before starting.

\subsection{Future expansion}

Magnification of the project is planned. Post-pilot, we aim to hold an event where the students can advertise their work to their whole school. This could include posters and talks, similar to a conference, which would be a valuable opportunity and responsibility for the students. Such an event would empower learners and educate them in the possibilities of their future. Giving students challenging research level data can be intimidating, but when they understand things not even master's students have done and can teach this to their fellow students and teachers, they are empowered with their potential and abilities. 


\section{Conclusion}

We have successfully developed and delivered a novel, engaging online pilot programme cocreating learning resources with students at a widening participation school, during a pandemic. The main benefits identified as a result of the project have been:

- Designing learning resources to enhance the possibility for students to choose STEM at university

- Connecting students with researchers

- Providing an interesting and innovative experience to students.

We are still waiting for the final conclusion, based on the results of the student surveys to get some hard data. Given the success of this project from student and teacher feedback, we have plans to apply for funding, permitting a wider roll-out, building up to a national project involving numerous universities.

\section{References}

ATLAS Collaboration (2008). The ATLAS experiment at the CERN large hadron collider. Jinst, 3, S08003. doi: 10.1088/1748-0221/3/08/S08003

ATLAS Collaboration. (2021). Data visualisation. ATLAS Open Data $13 \mathrm{TeV}$ Documentation. http://opendata.atlas.cern/release/2020/documentation/visualization/

Brown, M. E., \& Hocutt, D. L. (2015). Learning to use, useful for learning: a usability study of Google apps for education. Journal of Usability Studies, 10(4), 160-181. doi: $10.5555 / 2817322.2817327$

Burke, P. J. (2013). The right to higher education: Beyond widening participation.

Carnevale, A. P., Smith, N., \& Melton, M. (2011). STEM: Science Technology Engineering Mathematics. Georgetown University Center on Education and the Workforce.

Dollinger, M., Lodge, J., \& Coates, H. (2018). Co-creation in higher education: Towards a conceptual model. Journal of Marketing for Higher Education, 28(2), 210-231. doi: 10.1080/08841241.2018.1466756

Eccles, J. S., Barber, B. L., Stone, M., \& Hunt, J. (2003). Extracurricular activities and adolescent development. Journal of social issues, 59(4), 865-889. doi: 10.1046/j.00224537.2003.00095.x

Gibbons, P. (2002). Scaffolding language, scaffolding learning. Portsmouth, NH: Heinemann.

Graham, C. R. (2006). Blended learning systems. The handbook of blended learning: Global perspectives, local designs, 1, 3-21.

Kluyver, T., Ragan-Kelley, B., Pérez, F., Granger, B. E., Bussonnier, M., Frederic, J., ... \& et al. (2016). Jupyter Notebooks-a publishing format for reproducible computational workflows (Vol. 2016, pp. 87-90). 
Kourkoumelis, C., \& Vourakis, S. (2014). HYPATIA-an online tool for ATLAS event visualization. Physics Education, 49(1), 21. doi: 10.1088/0031-9120/49/1/21

Martin, L., \& Tapp, D. (2019). Teaching with Teams: An introduction to teaching an undergraduate law module using Microsoft Teams. Innovative Practice in Higher Education, 3(3), 58-66.

Murphy, P., \& Whitelegg, E. (2006). Girls in the physics classroom: A review of the research on the participation of girls in physics.

Wang, A. I., \& Tahir, R. (2020). The effect of using Kahoot! for learning-A literature review. Computers \& Education, 149, 103818. doi: 10.1016/j.compedu.2020.103818 